\title{
Molecular methods as ways of dealing with terminological difficulties in fungal ecology
}

\author{
Julia Budziszewska, Joanna Piątkowska \\ Department of Systematics and Plant Geography, University of Warsaw, \\ Al. Ujazdowskie 4, 00-478 Warsaw, Poland \\ e-mail: julia.budziszewska@biol.uw.edu.pl
}

\begin{abstract}
Many ecological terms are very difficult to define, or to apply to some groups of organisms. In the case of fungi, it is unclear how to speak of individuals, populations and species. Relying on morphological characters often gives ambiguous results. However, in recent years new techniques have been developed, techniques that provide us with robust tools, helpful in recognizing specific groups in nature. This paper aims to give a short overview of how molecular methods are used to delimitate species, individuals and populations in fungi.
\end{abstract}

Key words: molecular ecology, species, population, individual.

\section{The language of ecology}

Ecology, like any other science, has its own language, it consists of terms that often have different meaning than when used in common speech. That is because, unlike commonly used words, scientific terms need to be clearly and unambiguously defined, so that there is no "freedom of interpretation" of scientific statements.

Language of science is therefore unnatural, ruled by conventions. Ludwig Wittgenstein once compared language to an old town full of small crowded streets with various houses, surrounded by new suburbia with regular, symmetrical streets and buildings (Wittgenstein 1953). The old town resembles natural, common language, whereas suburbs represent newly constructed, artificial languages, with the language of mathematics and physics as a clear example. Where would ecology be within this metaphor? It is a science which deals with something very basic for human experience, the natural surroundings of human existence. Understanding nature was not only a sign of wisdom, but a simple necessity needed for survival. Thus ecology carries a huge luggage of intuitive preconceptions, naïve views connected to the subject of its interest. Such basic terms as species, individual, community and so forth, have been present for a long time in language and their meaning seems to be obvious to people. It makes defining them a difficult task. It means applying "the new suburbia" rules to the very center of the "town".

\section{Defining ecological terms}

Most controversies around definitions arise when they use the word "is" between definiendum (term defined) and definiens (phrase defining), that is when they are real definitions, aiming to articulate what the defined being actually is (Bombik 1985). Natural sciences, being empirical, also have the goal of "grabbing" reality and dealing with facts rather than abstract ideas. As a consequence, real definitions are in frequent use. This leads to aforementioned controversies, especially with new facts coming to light with the progress of our knowledge about living organisms. It seems impossible to express the great complexity of nature in terms universally applicable to every group of 
organisms. Yet it also seems impossible to give up using common universal terms. Instead, the metaphysical question "what the thing really is?" could be omitted, and substituted with: "what should you do to find this thing in nature?". In other words, real definitions could be substituted with operational definitions.

This somewhat pragmatic attitude is justified not only by the fact that the language of science (and therefore ecology) should be technical rather than philosophical. It also corresponds to the great recent progress of molecular techniques, providing us with a useful tool to operate on studied objects. The forthcoming part of this paper intends to show how molecular tools can be applied to dealing with terminological problems regarding fungi, a group of organisms with a very complex and unusual biology.

\section{Species definition within fungi}

The history of species concepts resembles various attitudes naturalists had towards this subject, and also more general changes in mentality. These concepts are often grouped in categories as follows: morphological, biological and phylogenetic (Taylor et al. 2000). Each of them uses different criteria for recognizing species. Mayden, however, proposed another grouping, dividing species concepts into theoretical and operational (Mayden 1997). Those mentioned above would all fall into operational concepts, as they all focus on the way of finding rather than defining species. One truly theoretical concept would be Wiley's evolutionary species concept, as it describes species as "(...) a single lineage of ancestor-descendant populations which maintains its identity from other such lineages and which has its own evolutionary tendencies and historical fate" (Wiley 1978). Contemporary researchers would probably agree with this theory, however it leaves them with no applicable criteria. Usually it becomes a matter of individual practice, which of the operational concepts should one use when working with specific group of organisms (Taylor et al. 2000). It should be stressed here, that in fact, as de Queiroz (2007) pointed out, it is not the concept of species, of what a species really is, that is so controversial. Researchers generally agree that a species is a distinctly evolving metapopulation lineage (de Quierez 2007). It is the delimitation of this lineage that is unclear, and there are different ways of doing it. But when it comes to fungi, each of these concepts has its difficulties (Tab. 1), and applying one may give different results than applying another.

Recognizing species using morphological (developmental, biochemical etc.) characters is the most common practice today. It also has a long history, as it is the way people commonly group objects into categories: with characters they can observe. It is a result of typological thinking, present in common knowledge and in science starting from the first, pre-Linnaean taxonomists. Applying it to fungi meets many obstacles, the main one being their great intraspecific morphological variation, up to pleomorphic life cycles. With new facts becoming known about anamorph - teleomorph connections, it is frequently shown, that asexual fungi described as two different species turn out to be merely life stages of one fungus, genetically identical (Hawksworth 2004). Furthermore, some anamorphic genera described using morphological characters may turn out to contain species that are in fact representatives of different teleomorphic genera or even families. Graphium putredinis (Corda) S. Hughes, for example, is the anamorph of Petriella sp. While Graphium calicioides (Fr.) Cooke and Massee revealed to be the anamorph of Chaetosphaeria sp. (Okada et al. 1998). Resolving the problem described above is not be possible without the use of molecular techniques.

Biological concept, in its most commonly known version expressed by Mayr, who described species as “(...) groups of actually or potentially interbreeding natural populations which are reproductively isolated from other such groups" (Mayr 1940), uses the criterion of mating as a sign of potential genetical continuity. It is also hardly applicable to fungi, with $20 \%$ of species without known

Table 1. Comparison of species recognition methods applied to fungi

\begin{tabular}{|l|l|l|}
\hline \multicolumn{1}{|c|}{ METHOD } & \multicolumn{1}{|c|}{ MAIN ADVENTAGES } & \multicolumn{1}{c|}{ MAIN DISADVENTAGES } \\
\hline Morphological & $\begin{array}{l}\text { - easy to apply } \\
\text { intuitive }\end{array}$ & $\begin{array}{l}\text { - overlooks cryptic species } \\
- \text { problems with pleomorphic taxa }\end{array}$ \\
\hline Biological & $\begin{array}{l}\text { - reveals reproductive communities } \\
- \text { reflects natural lineages }\end{array}$ & $\begin{array}{l}\text { - cannot be applied in many fungal groups like asexual } \\
\text { species, } \\
\text { mating test often impossible to perform }\end{array}$ \\
\hline Phylogenetic & $\begin{array}{l}- \text { lacks the disadvantages of previous methods } \\
- \text { can be applied to every group } \\
\text { - provides objective quantitative data }\end{array}$ & - arbitrary criteria of species delimitation \\
\hline
\end{tabular}


sexual stages, and many strands of the sexual stages unable to mate in culture. Some of the species, especially among basidiomycetes, have multiple mating loci, which frequently results in mating incompatibility, as there can be up to 8 sexes (Taylor et al. 2000). What is more, in fungi mating does not necessarily mean interaction between different individuals (heterothallic mating), as some species are self-mating (homothallic). Meiospores are therefore produced clonally. Also, recombination can occur without mating, due to parasexual processes (self-recombination). As a result, the distinctions between clonal reproduction and recombination does not correspond to the distinction between mitotic and meiotic reproduction, as in other groups of organisms (Taylor et al. 1999).

The phylogenetic concept is based on the criterion of monophyly, which can be recognized by examining molecular, but also morphological characters (Hennig 1965). Taxa are monophyletic when they share common evolutionary history, therefore it seems that phylogenetic concept brings us as close as we can get to evolutionary species. However, certain assumptions regarding the course of evolution need to be made in order to apply this concept. As differences in nucleotide sequence appear to come before differences in morphology and mating compatibility (in most cases), they seem to resemble the essence of what a species actually is (Taylor et al. 2000). This can be misleading and make us misinterpret the observed changes in DNA sequence, as our knowledge about the relation between genotype and expressed phenotype is still very modest. Still, when it goes to recognizing species of fungi in nature, phylogenetic concept gives best results out of all the aforementioned; phylogenetic methods helped to resolve relationships in many systematic groups (Okada et al. 1998), not only fungal (Paszko 2002).

Phylogenetic methods are, however, often criticized for using arbitrary criteria of species delimitation. How can we tell what is a species taxon, and what is a reproductive community (Rieseberg et al. 2006)? Because of the frequent horizontal gene transfer it is difficult to decide what is the real unit of evolution (see Slot \& Hibbett 2007). Using molecular markers can meet some methodological problems. The idea is that we trace polymorphism in a gene, assuming that evolution of this gene is concordant with the evolution of the species, and individuals of one species share the same polymorphism (Baldauf 2003). But what if the locus used as a marker is polymorphic within species? What if two species share polymorphism in this locus? What if the locus is a subject to balancing selection? The risk of those situations leading to overlooking or creating unnecessary species can be reduced to minimum by using several polymorphic loci. It is also recommended to use neutral loci, so that the rate of changes in sequence reflects time, and not some kind of selection. This method is referred to as Genealogical Concordance Phylgenetic Species Recogni- tion (GCPSR; Taylor et al. 2000). It is based on creating genealogies for several genes, and then combining them into one genealogical tree. Some genealogies can be in conflict due to recombination among individuals within one species, but there should be concordant branches in now phylogenetic tree. This is a result of fixed genetic isolation of a species. Therefore, concordant branch indicates species, whereas inconcordant branches show intraspecific variation. So far, in fungi, this method had produced results more reliable than morphological and biological methods of recognizing species (Taylor et al. 2000).

It is, however, worth noting that analysis of tree topology does not always give clear results. Sometimes trees calculated using different methods, or different loci, can vary significantly in topology. Some taxa can change their position among others, and fall within different groups from tree to tree. In such case, which method should be trusted? The usual solution is choosing a "better" gene, that reflects evolutionary relationships in the group correctly. How we make the choice remains arbitrary though. The criterion of concordance with previous studies of morphology and individual observations of the researcher seems to be in common use (Baldauf 2003). It makes choosing a tree more an art than a science.

Taxonomy certainly owes a great deal to genetic methods, especially with regard to "difficult" groups with cryptic species, hard to resolve relationships etc. (for example see Sung et al. 2007), it has to be said though that those methods alone cannot be treated as a sufficient tool for taxonomy. A combination of phenotypic, ecological and molecular data should be used together with the knowledge about the group of interest and intuition of the researcher (Okada et al. 1998). One should also keep in mind that speciation is a dynamic process; species arise, "live" their history, split, hybridize and go extinct all the time (Cracraft 1992). A taxonomist needs to set species boundaries carefully to give as much relevant information as possible about specific biological entity. Even though the very need for species delimitation in ecology can be questioned, there is still a need for operational, recognizable units (de Queiroz 2007; Landis \& Gargas 2007).

\section{Individual definition in fungal populations}

Other problematic definitions are "population" and "individual". The classical ecology textbooks define population as a group of individuals belonging to the same species and occupying common territory (Odum 1982). With reference to fungi this definition is not precise enough. As it has already been pointed out, even the mere concept of species is not well defined. What is more, the definition of an individual is also not clear in case of fungi. Even if there is nothing new in the statement that fruitbodies are integral 

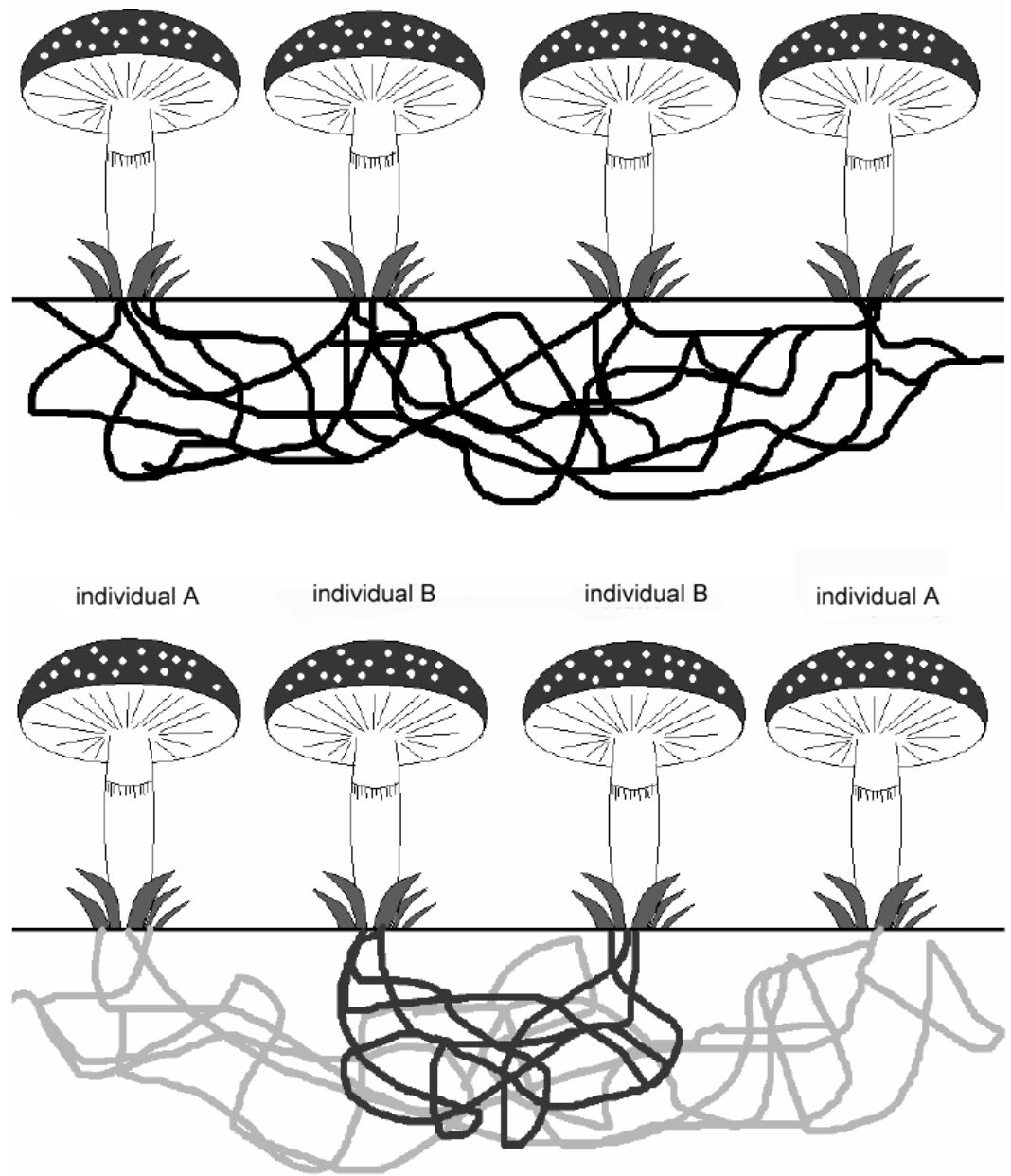

Figure 1. Complexity of underground hyphal connections among fungal fruitbodies

part of underground mycelium, for years in fungal populations studies each of them has been treated as individual (Bujakiewicz 1992). As shown in figure 1, it is hard to know if four carpophores belong to the same hypha or to two, three or even four different hyphal systems. Treating each fruitbody as individual seems to be very questionable. For example, it is easy to imagine one human being hidden behind the curtain with two hands poked out. While looking at those hands, it is hard to tell if there are two individuals or if they belong to one person. There are some differences between two hands of a single person, nevertheless we all agree they are organs of the same individual. In this case it is easy to check if those hands belonged to one person, as it is enough to draw back the curtains. In case of fungal carpophores situation is much more complicated. Usually there are lots of hyphal systems hidden underground, and even after shoving away the soil it is not be possible to distinguish which carpophores arise from the same mycelium. Until today there is no general guideline to how the group of carpophores should be treated, while it is clear that the analysis of the structure and functioning of population cannot be done before the clear definition of individual and population is set.

According to definition given by Santelices (1999), an individual is a being derived from one cell. Such biological individual can be described by three main features: 1 - genetic uniqueness, 2 - genetic homogeneity and 3 - autonomy (Santelices 1999). Therefore, two new terms recently appeared in population ecology: genet and ramet. The ramet is differentiated on the basis of phenotypic (morphological and physiological) features while the genet is usually defined as the genetic individual that develops from the zygote and that produces ramets vegetatively (Harper \& White 1974; Scrosati 2002). This way the individuals belonging to one genet should have identical genotype (Koide et al. 2007). As clones, they represent genetic uniqueness and homogeneity (Santelices 1999). However, somatic, spontaneous mutations rates are 
Table 2. Comparison of molecular marker techniques used in genet identification

\begin{tabular}{|c|c|c|c|}
\hline METHOD & NAME ABBREVIATION & MAIN ADVENTAGES & MAIN DISADVENTAGES \\
\hline $\begin{array}{l}\text { Amplified Fragment } \\
\text { Length Polymorphism }\end{array}$ & AFLP & $\begin{array}{l}\text { - highly efficient } \\
\text { - possibility of comparing whole genomes } \\
\text { - highly reproducible } \\
\text { - no prior sequence information is needed }\end{array}$ & $\begin{array}{l}\text { - laborious protocol } \\
\text { - generate huge quantities of } \\
\text { information thus results evaluation } \\
\text { can be difficult } \\
\text { - AFLP markers display dominance }\end{array}$ \\
\hline $\begin{array}{l}\text { Random Amplified } \\
\text { Polymorphic DNA }\end{array}$ & RAPD & $\begin{array}{l}\text { - simple protocol } \\
\text { - no prior sequence information is needed } \\
\text { - possibility of comparing whole genomes }\end{array}$ & $\begin{array}{l}\text { - large amount of DNA required } \\
\text { - sensitive to reaction conditions } \\
\text { - RAPD markers display dominance }\end{array}$ \\
\hline $\begin{array}{l}\text { Simple Sequence } \\
\text { Repeats }\end{array}$ & SSR & $\begin{array}{l}\text { - many loci can be analyzed } \\
\text { - easy statistical analysis } \\
\text { - can use old or degraded DNA } \\
\text { - automation possible } \\
\text { - fast and cheap protocol } \\
\text { - reveals all alleles of given locus }\end{array}$ & $\begin{array}{l}\text { - about } 10 \text { loci need to be tested } \\
\text { - hard to establish reaction condition }\end{array}$ \\
\hline $\begin{array}{l}\text { Single Nucleotide } \\
\text { Polymorphism }\end{array}$ & SNP & $\begin{array}{l}\text { - PCR product can be small } \\
\text { - can use old or degraded DNA } \\
\text { - automation possible } \\
\text { - common in genome } \\
\text { - no stutter products }\end{array}$ & $\begin{array}{l}\text { - only two alleles can be analyzed } \\
\text { - expensive } \\
\text { - a lot of SNPs have to be analyzed } \\
\text { to get some level of information }\end{array}$ \\
\hline $\begin{array}{l}\text { Restriction Fragment } \\
\text { Length Polymorphism }\end{array}$ & RFLP & $\begin{array}{l}\text { - highly discriminating } \\
\text { - only } 5-6 \text { loci need be tested } \\
\text { - reveals all alleles of given locus }\end{array}$ & $\begin{array}{l}\text { - high quality DNA required } \\
\text { - large amount of DNA required } \\
\text { - slow and expensive protocol } \\
\text { - can not be automated } \\
\text { - standardization and statistical } \\
\text { evaluations are difficult }\end{array}$ \\
\hline
\end{tabular}

between $10^{-4}$ and $10^{-6}$ mutations per gene per generation (Hartl \& Jones 2005). The second problem of the definition given above is that only the zygote can be considered as the initial cell of genet (Scrosati 2002). This point of view is strongly questionable taking into account that we do not know the sexual reproduction in many fungal lineages. Thus the updated definition of genet defines it as "the free-living individual that develops from one original zygote, parthenogenetic gamete, or spore and that produces ramets vegetatively during growth" (Scrosati 2002).

Hence, two carpophores of the same mycelium certainly cannot be treated as "the free living individuals". However, as it was mentioned above, in the case of fruitbodies it is hard to guess if they belong to one or to several different mycelia. Thus the only way to delimit genets is to reveal if the analyzed fruit-bodies have originated from one or several different initial cells. The more their genotypes are similar, the more it is possible that they are one individual (Guidot et al. 2001). At this point another methodical problem appears. In order to compare two genotypes, their complete sequences are required. Even though it is possible to achieve using contemporary molecular techniques, it is still extremely expensive. Fortunately there are already several different molecular marker techniques (Tab. 2) with which it is possible to get quite a good approximation of genome similarities.

\section{Genets identification using molecular techniques}

The easiest approximation of genomes similarity is achieved through sequencing of some chosen genome fragments. This method is often called single nucleotide polymorphism detection. SNP is literally single base pair variation, outside of coding sequence. SNPs exist all over the genome and they are much more common than Single Tandem Repeats (STR) which are further described. The method of SNPs detection consists of sequencing and comparing amplified fragments of DNA from the examined carpophores. Of course, there is a strong probability that differences between genomes could occur in different parts to those which are being amplified. Therefore, the more fragments are sequenced, the more reliable the 
result is. Even if sequencing is a very precise method, it is also quite expensive. Therefore instead of multiplying sequenced fragments, we can combine different methods of genome polymorphism detection (Fiore-Donno \& Martin 2001).

Instead of sequencing, we can compare only the length of DNA fragments from different carpophores. This method is called amplified fragment length polymorphism (Mueller \& Wolfenbarger 1999). As amplifying sequences is cheaper than their sequencing, there is a possibility of comparing more fragments. In order to increase the credibility of this comparison, we can combine this method with, for example, random amplified polymorphic DNA (RAPD). This technique is based on using short primers, which allow to amplify specific random fragments of the genome. The comparison of their length supplies us with additional information about genomes' similarity (Williams et al. 1990). Unfortunately, high molecular weight of DNA is required and numerous precautions are needed to avoid contamination of DNA. Even highly standardized experimental procedures are sensitive to reaction conditions. Due to those disadvantages RAPD is currently rarely used (Freeland 2005). Another method relying on fragment length polymorphism is simple sequence repeats (or Single Tandem Repeats; STR). The so-called microsatelites are very common fragments of DNA which consist of tandem repetition of some simple motif. The differences in number of motif's repetition, visible in length of fragment, reveal differences between chosen genets (Tagou \& Moussard 2003). It is worth noting that, apart from the amplification of fragments, there also exists a number of other approaches to genomes comparison.

The restriction fragment length polymorphism is one of such techniques. When the restriction enzymes recognize the sequence specific for them, they cut the DNA in this place. Therefore electrophoretic comparison of length of digested DNA fragments can reveal sequence differences. Furthermore, using several different enzymes increases the credibility of such research (Freeland 2005).

The main problem with all methods based on amplified products' length comparison is their limitation to the size of the given fragment. Classical electrophoretic methods allow us to compare only those fragments, which are composed of 100 up to 50'000 nucleotides. Products which are bigger cannot be separated (Tagou \& Moussard 2003). The pulse field gel electrophoresis described in 1985 by Carle and Olson allows to separate fragments of even 10'000'000 nucleotides, and it makes it possible to compare the whole chromosomes. The principle of this technique relies on using two shifted electric fields. The speed of reorientation of differently sized molecules is, of course, visible. The bigger molecules change direction of separation slower than the smaller ones (Schwartz \& Cantor 1984).
Finally, the secondary conformation of DNA fragments also depends on their nucleotide sequence, and the last group of genome polymorphism detection methods relies on revealing conformation changes. One of such techniques is denaturing gel gradient electrophoresis (DGGE). It is a very accurate method which allows to detect change even in a single nucleotide. The basis of DGGE is separation of DNA amplified fragments in agarose gel with increasing concentration of denaturating agent. It can be chemical agent or temperature (temperature gel gradient electrophoresis). When a molecule, moving through the gel, reaches the concentration of denaturating agent which is sufficient to their DNA strands separation, it stops. Even one nucleotide change is enough to influence the concentration of denaturating agent required for strands separation (Muyzer et al. 1993). Another technique based on conformation polymorphism detection is single strand conformation polymorphism. Single strand conformation depends strongly on nucleotide sequence, so each change in DNA sequence can influence its spatial conformation. This method relies on heating the DNA fragment in order to cause its denaturation. After that, the single strands are separated in acrylamide gel. Thus, if there had been differences in DNA sequences which influenced the single strand conformation, it would be possible to observe it on gel electrophoresis (Tagou \& Moussard 2003).

As it has been shown, there are several methods which allow us to detect differences between genomes. Of course, a combination of different techniques increases the accuracy of results, but we have to remember that only the whole genome sequence can give exact information about genets' identity. Maybe one day the sequencing of whole genomes will become cheap enough to be used for identification of fungal individuals. On the other hand it is worth knowing that current opinions on fungal genetics bring clear species and individual definitions into question. In some fungal groups horizontal interspecific gene transfer by cell fusion can be observed (Kellner et al. 1993). This phenomenon proves that each operational definition of the above mentioned terms is merely an approximation of the reality which it seeks to describe.

In conclusion, the genet definition seems to be the best term redefining fungal individuals at the moment. Unfortunately, even though there are many molecular techniques enabling genome polymorphism detection, they provide us with a mere approximation of sought differences.

\section{Acknowledgements}

The authors would like to thank dr Marta Wrzosek, Przemysław Piątkowski and an anonymous reviewer for providing helpful comments on the manuscript. 


\section{References}

Baldauf S. L., 2003, Phylogeny for the faint of heart: a tutorial, Trends in Genetics 19 (6): 345-351.

Bombik M., 1985, O rodzajach definicji [About types of definitions], Miscellanea Logica 2: 17-239.

Bujakiewicz A., 1992, Badania mikosocjologiczne w zespole Ficario - Ulmetum campestris w rezerwacie "Wielka Kępa Ostromecka" nad Wisłą [Mycosociological research in the Ficario-Ulmetum campestris association in the „Wielka Kępa Ostromecka” reserve on the Vistula river], Acta Mycologica 27 (2): 277-290.

Carle G. F. \& Olson M. V., 1985, An electrophoretic karyotype for yeast, Proceedings of the National Academy of Science USA 82: 3756-3760.

Cracraft J., 1992, Species Concepts and Speciation Analysis, [in:] The Units of Evolution: Essays on the Nature of Species, MIT Press: 93.

Fiore-Donno A. M. \& Martin F., 2001, Populations of ectomycorrhizal Laccaria amethystina and Xerocomus spp. show contrasting colonization patterns in a mixed forest, New Phytologist 152: 533-542.

Freeland J. R., 2005, Molecular Ecology, John Wiley \& Sons, West Sussex.

Guidot A., Debaud J.C. \& Marmeisse R., 2001, Correspondence between genet diversity and spatial distribution of above- and below-ground populations of the ectomycorrhizal fungus Hebeloma cylindrosporum, Molecular Ecology 10 (5): 1121-1131.

Harper J. L. \& White J., 1974, The demography of plants, Annual Review of Ecology and Systematics 5: 419463

Hartl D. L. \& Jones E. W., 2005, Genetics: Analysis of Genes and Genomes, $6^{\text {th }}$ edition, Jones $\&$ Bartlett Publisher, Sudbury.

Hawksworth D., 2004, Limitation of dual nomenclature in pleomorphic fungi, Taxon 53(2): 596-598.

Hennig W., 1965, Phylogenetic Systematics, Annual Review of Entomology 10: 97-116.

Kellner M., Burmester A., Wöstermeyer A. \& Wöstermeyer J., 1993, Transfer of genetic information from the mycoparasite Parasitella parasitica to its host Absidia glauca, Current Genetics 23: 334-337.

Koide R. T., Shumway D. L., Xu B. \& Sharda J. N., 2007 , On temporal partitioning of a community of ectomycprrhizal fungi, New Phytologist 174 (2): 420 429.

Landis F. C. \& Gargas A., 2007, Using ITS2 secondary structure to create species-specific oligonucleotide probes for fungi, Mycologia 99 (5) : 681-692.

Mayden R. L., 1997, A hierarchy of species concepts: The denoument in the saga of the species problem, [in:] M. F. Claridge, A. H. Dawah, M. R. Wilson (eds.), Species: The Units of Biodiversity, Systematics Asso- ciation Special Volumes Series 54, Chapman \& Hall, London: 382-424.

Mayr E., 1940, Speciation phenomena in birds, American Naturalist 74: 249-278.

Mueller V. G. \& Wolfenbarger L. L., 1999, AFLP genotyping and fingerprinting, Trends in Ecology and Evolution 14: 389-394.

Muyzer G., de Waal E. C. \& Uitterlinden A. G., 1993, Profiling of complex microbial populations by denaturing gradient gel electrophoresis analysis of polymerase chain reaction-amplified genes coding for $16 \mathrm{~S}$ rRNA, Applied and Environmental Microbiology 59: 695-700.

Odum E., 1982, Podstawy ekologii, wyd. 3 [Fundamentals of ecology, third. edition], Państwowe Wydawnictwo Rolnicze i Leśne, Warszawa.

Okada G., Seifert K. A., Takematsu A., Yamaoka Y., Miyazaki S. \& Tubaki K., 1998, A molecular phylogenetic reappraisal of the Graphium complex based on 18S rDNA sequences, Canadian Journal of Botany 76: 1495-1506.

Paszko B., 2002, Hybridization as a cause of taxonomic problems in the genus Calamagrostis in Poland, Ecological Questions 2: 151-157.

Queiroz K. de, 2007, Species Concepts and Species Delimitation, Systematic Biology 56 (6): 879-886.

Rieseberg L. H., Wood T. E., Back E., 2006, The nature of plant species, Nature 440: 524-527.

Santelices B., 1999, How many kinds of individual are there?, Trends in Ecology and Evolution 14 (4): 152155.

Schwartz D. C. \& Cantor C. R., 1984, Separation of yeast chromosome-sized DNAs by pulsed field gradient gel electrophoresis, Cell 37 (1): 67-75.

Scrosati R., 2002, An updated definition of genet applicable to clonal seaweeds, bryophytes, and vascular plants, Basic and Applied Ecology 3: 97-99.

Slot J. C., \& Hibett D. S., 2007, Horizontal Transfer of a Nitrate Assimilation Gene Cluster and Ecological Transitions in Fungi: A Phylogenetic Study, PLoS ONE 2 (10): e1097.

Sung G. H., Hywel-Jones N. L., Sung J. M., Luangsa-Ard J. J., Shrestha B. \& Spatafora J. W., 2007, Phylogenetic classification of Cordyceps and the clavicipitaceous fungi, Studies in Mycology 57: 5-59.

Tagou D. \& Moussard C., 2003, Principes des techniques de biologie moléculaire, INRA éditions, Paris, 2003: 152-170.

Taylor J. W., Jacobson D. J. \& Fisher M. C., 1999, The Evolution of Asexual Fungi: Reproduction, Speciation and Classification, Annual Review of Phytopathology 37: 197-246.

Taylor J. W., Jacobson D. J., Kroken S., Kasuga T., Geiser T. M., Hibbet D. S. \& Fisher M. C., 2000, Phylogenetic 
species recognition and species concept in fungi, Fungal Genetics and Biology 31: 21-32.

Wiley E. O., 1978, The evolutionary species concept reconsidered, Systematic Zoology 27: 17-26.

Williams J. G. K., Kubelik A. R., Livak K. J., Rafalski J. A. \& Tingey S. V., 1990, DNA polymorphisms am- plified by arbitrary primers are useful as genetic markers, Nucleic Acids Research 18: 6531-6535.

Wittgenstein L., 1953, Philosophical Investigations, Blackwell Publishers, Oxford. 